\title{
Associations of Handgrip Strength with Prevalence of Rheumatoid Arthritis and Diabetes Mellitus in Older Adults
}

\author{
Junga Lee, Man-Gyoon Lee* \\ Graduate School of Physical Education, Sports Medicine and Science, Kyung Hee University, Yongin, Korea
}

Background: The purpose of this study was to investigate the association between handgrip strength and prevalence of rheumatoid arthritis and diabetes in older adults.

Methods: A total of 4,186 participants 65 years of age and older was included in the study, which utilized data from the fifth Korea National Health and Nutrition Examination Survey. Pearson's chi-square tests were used to explore the relationship between frequency of participation in physical activity and handgrip strength. The relationships between handgrip strength and prevalence of rheumatoid arthritis and diabetes were determined by logistic regression.

Results: Older adults with higher handgrip strength participated more frequently in walking (right hand, 3.71 day/wk; left hand, 3.80 day/wk), strength (right hand, 1.40 day/wk; left hand, 1.43 day/wk), and flexibility exercises (both hands, 2.08 day/wk) than those with lower handgrip strength (right hand, 2.83 day/wk and left hand, $2.81 \mathrm{day} / \mathrm{wk}$ for walking; right hand, $0.18 \mathrm{day} / \mathrm{wk}$ and left hand, $0.22 \mathrm{day} / \mathrm{wk}$ for strength; right hand, $1.17 \mathrm{day} / \mathrm{wk}$ and left hand, 1.24 day/wk for flexibility). Higher handgrip strength was associated with reduced prevalence of rheumatoid arthritis (right hand: odds ratio [OR], $0.29 ; 95 \%$ confidence interval [Cl], 0.16-0.52; $P<0.05$; left hand: $\mathrm{OR}, 0.20 ; 95 \% \mathrm{Cl}, 0.10-0.38 ; P<0.05)$ and diabetes (right hand: $\mathrm{OR}, 0.71 ; 95 \% \mathrm{Cl}, 0.57-0.89 ; P<0.05$; left hand: $\mathrm{OR}, 0.71 ; 95 \% \mathrm{Cl}, 0.58-0.88 ; P<0.05)$.

Conclusion: Enhanced handgrip strength was significantly associated with lower prevalence of rheumatoid arthritis and diabetes in older adults. Participating in physical activity should be recommended to older adults for maintaining handgrip strength.

Key words: Handgrip strength, Rheumatoid arthritis, Diabetes, Physical activity

\author{
Received August 11, 2019 \\ Reviewed September 3, 2019 \\ Accepted October 30, 2019 \\ *Corresponding author \\ Man-Gyoon Lee \\ https://orcid.org/0000-0002-7889-1558 \\ Graduate School of Physical Education, \\ Sports Medicine and Science, \\ Kyung Hee University, Global Campus, \\ 1732 Deogyeong-daero, Giheung-gu, \\ Yongin 17104, Korea \\ Tel: +82-31-201-3753 \\ Fax: +82-31-201-3743 \\ E-mail:mlee@khu.ac.kr
}

\section{INTRODUCTION}

The average worldwide life expectancy was 71.4 years in $2015 .{ }^{1}$ In the country with the longest life expectancy, the average was 82.3 years, with women living 4.6 years longer than men. ${ }^{1}$ More people are interested in living longer and healthier lives without disease. To increase life expectancy and improve health outcomes, physical fitness has become a popular preventative course.

Physical fitness is measured by diverse methods. Handgrip strength is known as an easy way to gauge physical fitness and is a reliable predictor of mortality and disease. A recent meta-analysis reported that older adults with lower handgrip strength exhibited $37 \%$ higher all-cause mortality than those with higher handgrip strength. ${ }^{2}$ Handgrip strength was also associated with prevalence of chronic diseases, including Alzheimer disease in older American adults, falls in older Chinese adults, and osteoarthritis, depression, diabetes, and multimorbidity in older adults living in Hong Kong. ${ }^{3-5} \mathrm{Ko}-$ rean adults more than 60 years old, who compose about $15 \%$ of 
the country's total population, suffer from several chronic diseases, including rheumatoid arthritis and diabetes. ${ }^{6}$ Increased levels of inflammatory agents such as C-reactive protein (CRP) and interleukin-6 (IL-6) are associated with rheumatoid arthritis and diabetes. ${ }^{7}$ The cause of rheumatoid arthritis is inflammation of connective tissue, skeletal muscle, and skeletal muscle-related structures. Patients with diabetes have a higher incidence of rheumatoid arthritis. ${ }^{8}$ Aging escalates loss of muscle mass, and older adults with rheumatoid arthritis and diabetes often suffer from severely damaged skeletal muscle., ${ }^{9}$

Participating in physical activity has been associated with increased muscle mass as assessed by higher handgrip strength. ${ }^{11}$ This may contribute to a reduction in the prevalence of rheumatoid arthritis and diabetes. Depending on physical activity frequency, modality, and duration, the level of handgrip strength achieved could inform guidelines for prevention of rheumatoid arthritis and diabetes in older adults. It is currently assumed that older adults with higher handgrip strength participate in more physical activity and experience less rheumatoid arthritis and diabetes than older adults with lower handgrip strength. This study investigated the relationship between handgrip strength and frequency of participating in walking and strength and flexibility exercises. This study also explored the association between handgrip strength and prevalence of both rheumatoid arthritis and diabetes in older adults.

\section{METHODS}

\section{Study subjects, ethics statement, and data access}

Data gathered in 2014 and 2015 by the Korea National Health and Nutrition Examination Survey (KNHANES), a nationally representative survey that employs a stratified multistage probability sampling design, were used for this study. The KNHANES dataset was approved by the Institutional Review Board of the Korea Centers for Disease Control and Prevention (2013-12EXP-03-5C). As researchers used the KNHANES dataset for purposes of this study, further IRB approval was not required. All participants provided written informed consent to the KNHANES, and the dataset did not include any identifying participant information. Participants were randomly selected using household registries based on geographical area, sex, and age. This study had a cross-sectional design, and the participants were adults older than 60 years $(n=4,186)$.

\section{Survey questionnaires}

A self-reporting questionnaire survey was employed to obtain health-related information, including whether participants had been diagnosed with rheumatoid arthritis or diabetes. Participants were asked, "Have you been diagnosed with rheumatoid arthritis?" or "Have you been diagnosed with diabetes?" Answer options were "yes" or "no." The survey questionnaire also collected information on the amount of participation in walking and strength and flexibility exercises using the questions: "How many days did you participate in walking last week?," "How many days did you participate in strength exercise last week?," and "How many days did you participate in flexibility exercise last week?" Participants selected the number of days per week for each question. Participants were also asked to supply their current smoking status.

\section{Measurements}

All participants undertook a 12-hour overnight fast the day before the first measurement. The participants wore light clothing without shoes to measure body weight and height. Body mass index (BMI) was calculated as weight $(\mathrm{kg})$ divided by height squared $\left(\mathrm{m}^{2}\right)$. Waist circumference was measured from the narrowest point around the navel. Systolic and diastolic blood pressure were measured three times by a nurse using a mercury blood-pressure monitor (Hico, Tokyo, Japan), and the three measurements were averaged. Handgrip strength was measured three times on each the right and left hands using a digital grip strength dynamometer (TKK 5401; Takei, Tokyo, Japan). Averages of handgrip strength were used. Blood samples were drawn, centrifuged, refrigerated, and sent to a laboratory to determine levels of plasma glucose, total cholesterol, triglycerides, high-density lipoprotein cholesterol, and low-density lipoprotein cholesterol.

\section{Statistical analysis}

This study analyzed the data using KNHANES guidelines. Basic characteristics of participants were analyzed by descriptive analysis. Handgrip strength was divided into quartiles. Pearson's chi-square tests were conducted to determine the relationship between frequency of participation in physical activity (including walking and 
strength and flexibility exercises) and handgrip strength, as well as the relationships between rheumatoid arthritis and diabetes and handgrip strength. Logistic regression analysis was used to investigate any association between handgrip strength and prevalence of rheumatoid arthritis and diabetes. All statistical analyses were performed using IBM SPSS version 23.0 (IBM Corp., Armonk, NY, USA), and the statistical significance was $P<0.05$.

\section{RESULTS}

\section{Participants}

The average age of the 4,186 study participants was $69.75 \pm$ 0.21 years. Basic participant characteristics are listed in Table 1. Of the total participants, $88.5 \%(n=3,704)$ were right-handed, $4.6 \%$ ( $n=193)$ were left-handed, and 6.9\% $(n=289)$ were ambidextrous. Participants who had rheumatoid arthritis comprised 2.3\% $(n=95)$ of the population, including both males $(0.9 \%, \mathrm{n}=17)$ and females $(3.3 \%, n=78)$. Diabetes was reported in $16.2 \%(n=677)$, consisting of $17.7 \%(n=320)$ of males and $15.0 \%(n=357)$ of females. Handgrip strength was divided into quartiles. For the right hand in males,

Table 1. Basic characteristics of participants, including handgrip strength, rheumatoid arthritis, diabetes

\begin{tabular}{lccc}
\hline Variable & Total $(\mathrm{n}=4,186)$ & Male $(\mathrm{n}=1,813)$ & Female $(\mathrm{n}=2,373)$ \\
\hline Age $(\mathrm{yr})$ & $69.75 \pm 0.21$ & $69.02 \pm 0.20$ & $70.31 \pm 0.22$ \\
Height $(\mathrm{cm})$ & $157.80 \pm 0.23$ & $165.54 \pm 0.17$ & $151.59 \pm 0.23$ \\
Weight $(\mathrm{kg})$ & $60.09 \pm 0.22$ & $65.18 \pm 0.22$ & $56.12 \pm 0.27$ \\
BMI $\left(\mathrm{kg} / \mathrm{m}^{2}\right)$ & $24.07 \pm 0.06$ & $23.78 \pm 0.06$ & $24.30 \pm 0.09$ \\
WC $(\mathrm{cm})$ & $84.53 \pm 0.16$ & $86.06 \pm 0.20$ & $83.34 \pm 0.22$ \\
SBP $(\mathrm{mmHg})$ & $126.99 \pm 0.39$ & $125.76 \pm 0.53$ & $127.94 \pm 0.36$ \\
DBP $(\mathrm{mmHg})$ & $72.95 \pm 0.25$ & $73.41 \pm 0.26$ & $72.59 \pm 0.29$ \\
Glucose $(\mathrm{mg} / \mathrm{dL})$ & $108.24 \pm 0.40$ & $110.09 \pm 0.62$ & $106.70 \pm 0.56$ \\
HbA1c $(\%)$ & $6.06 \pm 0.01$ & $6.05 \pm 0.02$ & $6.06 \pm 0.02$ \\
TC $(\mathrm{mg} / \mathrm{dL})$ & $188.27 \pm 0.50$ & $181.41 \pm 0.72$ & $194.00 \pm 0.90$ \\
TG $(\mathrm{mg} / \mathrm{dL})$ & $141.21 \pm 1.51$ & $148.05 \pm 1.90$ & $135.49 \pm 1.97$ \\
HDL-C $(\mathrm{mg} / \mathrm{dL})$ & $48.60 \pm 0.17$ & $46.61 \pm 0.22$ & $50.27 \pm 0.25$ \\
LDL-C (mg/dL) & $112.54 \pm 0.71$ & $107.47 \pm 0.97$ & $116.93 \pm 0.92$ \\
Right handgrip strength $(\mathrm{kg})$ & $26.58 \pm 0.20$ & $33.67 \pm 0.22$ & $20.38 \pm 0.18$ \\
Left handgrip strength $(\mathrm{kg})$ & $25.45 \pm 0.21$ & $32.55 \pm 0.20$ & $19.27 \pm 0.17$ \\
Rheumatoid arthritis & $95(2.3)$ & $17(0.9)$ & $78(3.3)$ \\
Diabetes mellitus & $677(16.2)$ & $320(17.7)$ & $357(15.0)$ \\
\hline
\end{tabular}

Values are presented as mean \pm standard deviation or number $(\%)$.

$\mathrm{BMI}$, body mass index; WC, waist circumference; SBP, systolic blood pressure; DBP, diastolic blood pressure; HbA1C, glycosylated hemoglobin; TC, total cholesterol; TG, triglycerides; HDL-C, high-density lipoprotein cholesterol; LDL-C, low-density lipoprotein cholesterol. the first quartile was less than $29.16 \mathrm{~kg}$, with between $29.17 \mathrm{~kg}$ and $34.13 \mathrm{~kg}$ for the second quartile, between $34.14 \mathrm{~kg}$ and $38.32 \mathrm{~kg}$ for the third quartile, and more than $38.33 \mathrm{~kg}$ for the fourth quartile. for the fourth quartile. For the right hand in females, the first quartile was less than $16.87 \mathrm{~kg}$, with between $16.87 \mathrm{~kg}$ and $20.53 \mathrm{~kg}$ for the second quartile, between $20.54 \mathrm{~kg}$ and $24.10 \mathrm{~kg}$ for the third quartile, and more than $24.11 \mathrm{~kg}$ for the fourth quartile. For the left hand in males, the first quartile was less than $29.09 \mathrm{~kg}$, with between $29.09 \mathrm{~kg}$ and $33.97 \mathrm{~kg}$ for the second quartile, between $33.98 \mathrm{~kg}$ and $38.40 \mathrm{~kg}$ for the third quartile, and more than 38.41 $\mathrm{kg}$ for the fourth quartile. For the left hand in females, the first quartile was less than $16.03 \mathrm{~kg}$, with between $16.03 \mathrm{~kg}$ and 19.53 $\mathrm{kg}$ for the second quartile, between $19.54 \mathrm{~kg}$ and $22.67 \mathrm{~kg}$ for the third quartile, and more than $22.68 \mathrm{~kg}$ for the fourth quartile.

\section{Amount of physical activity, including walking, strength exercise, and flexibility exercise, according to handgrip strength}

Frequency of participation in physical activity is presented in Fig. 1 (right hand) and Fig. 2 (left hand). Compared with the first quartile, the second, third, and fourth quartiles had higher frequencies of physical activity participation, including walking (1st: 2.83 day/wk, 2nd: 3.57 day/wk, 3rd: 3.90 day/wk, and 4th: 3.71 day/wk, $P<0.05$ in right hand and 1st: 2.81 day/wk, 2nd: 3.75 day/wk, 3rd: 3.75 day/wk, and 4th: 3.80 day/wk, $P<0.05$ in left hand), and strength exercise (1st: 0.18 day/wk, 2nd: 0.44 day/wk, 3rd: 0.82 day/wk, and 4th: 1.40 day/wk, $P<0.05$ in right hand and 1st: 0.22 day/wk, 2nd: 0.51 day/wk, 3rd: 0.73 day/wk, and 4th: 1.43 day/wk, $P<0.05$ in left hand) and flexibility exercises (1st: 1.17 day/wk, 2nd: 1.89 day/wk, 3rd: 1.95 day/wk, and 4th: 2.08 day/wk, $P<0.05$ in right hand and 1st: 1.24 day/wk, 2nd: 1.91 day/wk, 3rd: 1.81 day/wk, and 4th: 2.08 day/wk, $P<0.05$ in left hand) for both the right and left hands based on Pearson's chi-square tests.

\section{Associations of prevalence of rheumatoid arthritis and diabetes and handgrip strength according to sex}

The prevalence of rheumatoid arthritis and diabetes in relation to the quartiles of handgrip strength are presented in Table 2 . When the first quartile of handgrip strength is considered as a reference, the prevalence of rheumatoid arthritis and diabetes was sig- 


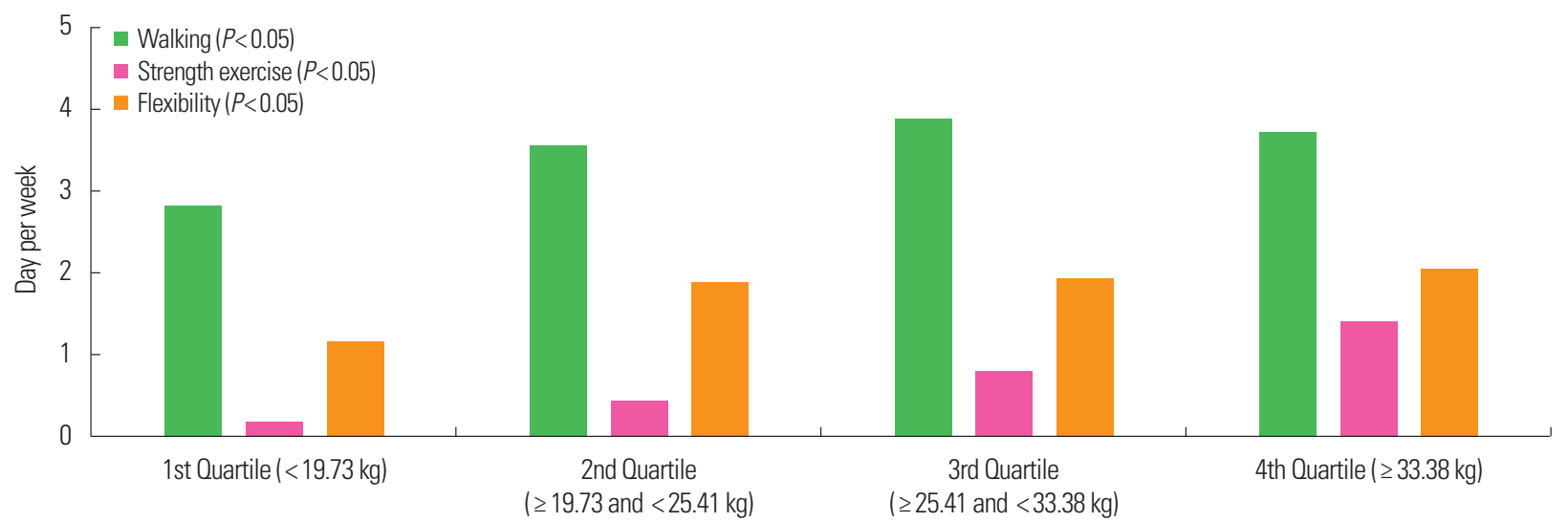

Figure 1. Amount of physical activity participation, including walking, strength exercise, and flexibility according to the right handgrip strength. Older adults with higher handgrip strength (4th quarter) had higher participating in walking, strength exercise and flexibility in the right hand based on Pearson's chi-square tests $(P<0.05)$ compared with the 1st, 2nd, and 3rd quarters of handgrip.

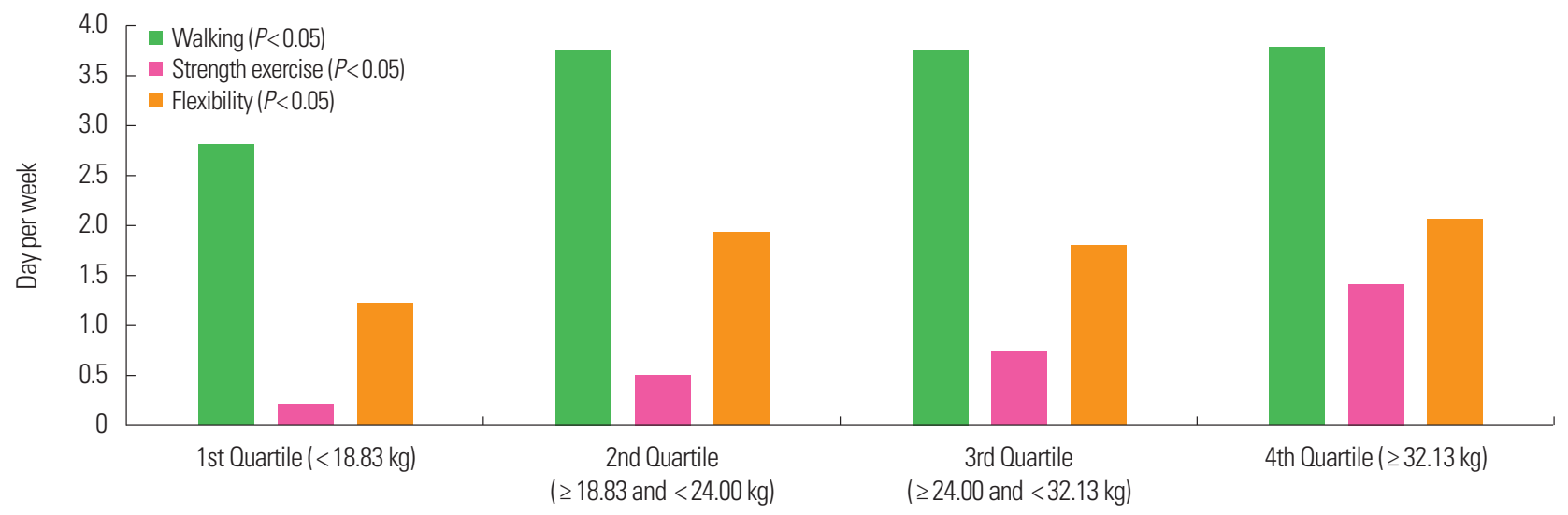

Figure 2. Amount of physical activity participation, including walking, strength exercise, and flexibility according to the left handgrip strength. Older adults with higher handgrip strength (4th quarter) had higher participating in walking, strength exercise and flexibility in the left hand based on Pearson's chi-square tests $(P<0.05)$ compared with the 1st, 2nd, and 3rd quarters of handgrip.

nificantly lower in the second, third, and fourth quartiles after adjusting for age, smoking, and BMI. The greatest reduction (80\%; odds ratio, 0.20 ; $95 \%$ confidence interval, $0.10-0.38)$ in the prevalence of rheumatoid arthritis was in the fourth quartile.

\section{DISCUSSION}

This study found that older adults with higher handgrip strength participated more frequently in walking and strength and flexibility exercises. Additionally, older adults with higher handgrip strength had lower rates of rheumatoid arthritis and diabetes than older adults with lower handgrip strength. Thus, it is recommended that patients with rheumatoid arthritis and diabetes participate in walking and strength and flexibility exercises to reduce the risk of chron- ic inflammation.

Older adults with high handgrip strength participated in more days of walking and strength and flexibility exercises than those with low handgrip strength. Several previous studies have reported the beneficial effects of exercise for patients with rheumatoid arthritis and diabetes. ${ }^{12-15}$ Aerobic and anaerobic exercise has been shown to improve physical fitness and the ability to perform activities of daily living and to reduce fatigue and joint pain. ${ }^{12,13}$ Also, a 12-week, upper extremity exercise training program helps improve handgrip strength, disability, function, self-efficacy, and disease activity in patients with rheumatoid arthritis. ${ }^{14}$ Speed and Campbell ${ }^{15}$ found that patients with rheumatoid arthritis who completed a 12-week, isometric handgrip-strength exercise program improved neural adaptation as measured by magnetic resonance imaging 
Table 2. Associations between prevalence of rheumatoid arthritis and diabetes and handgrip strength according to sex

\begin{tabular}{|c|c|c|c|}
\hline \multirow{2}{*}{ Variable } & & \multirow{2}{*}{$\frac{\text { Rheumatoid arthritis }}{\text { Odds ratio }(95 \% \mathrm{Cl})}$} & \multirow{2}{*}{$\frac{\text { Diabetes mellitus }}{\text { Odds ratio (95\% Cl) }}$} \\
\hline & & & \\
\hline \multicolumn{4}{|l|}{ Right } \\
\hline \multirow{2}{*}{$\begin{array}{l}\text { 1st Quartile } \\
\qquad(<19.73 \mathrm{~kg})\end{array}$} & Male & 1 & 1 \\
\hline & Female & 1 & 1 \\
\hline \multirow{2}{*}{$\begin{array}{l}\text { 2nd Quartile } \\
\qquad(\geq 19.73 \text { and }<25.41 \mathrm{~kg})\end{array}$} & Male & $1.88(5.40-6.53)$ & $0.44(0.13-1.07)$ \\
\hline & Female & $0.53(0.24-1.19)$ & $0.79(0.53-1.16)$ \\
\hline \multirow{2}{*}{$\begin{array}{l}\text { 3rd Quartile } \\
\qquad(\geq 25.41 \text { and }<33.38 \mathrm{~kg})\end{array}$} & Male & $0.18(0.06-0.50)^{*}$ & $0.54(0.27-1.05)$ \\
\hline & Female & $0.32(0.15-0.70)^{*}$ & 0.74 (0.50-1.08) \\
\hline \multirow{2}{*}{$\begin{array}{l}\text { 4th Quartile } \\
\qquad(\geq 33.38 \mathrm{~kg})\end{array}$} & Male & $0.20(0.08-0.50)^{*}$ & $0.25(0.12-0.52)^{*}$ \\
\hline & Female & $0.30(0.12-0.76)^{*}$ & $0.64(0.42-0.98)^{*}$ \\
\hline \multicolumn{4}{|l|}{ Left } \\
\hline \multirow{2}{*}{$\begin{array}{l}\text { 1st Quartile } \\
\qquad(<18.83 \mathrm{~kg})\end{array}$} & Male & 1 & 1 \\
\hline & Female & 1 & 1 \\
\hline \multirow{2}{*}{$\begin{array}{l}\text { 2nd Quartile } \\
\qquad(\geq 18.83 \text { and }<24.00 \mathrm{~kg})\end{array}$} & Male & $2.30(0.90-5.86)$ & 0.71 (0.49-1.05) \\
\hline & Female & $0.41(0.18-0.96)^{*}$ & 0.81 (0.57-1.16) \\
\hline \multirow{2}{*}{$\begin{array}{l}\text { 3rd Quartile } \\
\qquad(\geq 24.00 \text { and }<32.13 \mathrm{~kg})\end{array}$} & Male & $1.53(0.38-6.13)$ & $0.40(0.28-0.58)^{*}$ \\
\hline & Female & $0.16(0.05-0.52)^{*}$ & $0.67(0.45-1.00)$ \\
\hline \multirow{2}{*}{$\begin{array}{l}\text { 4th Quartile } \\
\qquad(\geq 32.13 \mathrm{~kg})\end{array}$} & Male & $0.65(0.12-3.60)$ & $0.43(0.28-0.66)^{*}$ \\
\hline & Female & $0.43(0.19-0.96)^{*}$ & $0.62(0.42-0.91)^{*}$ \\
\hline
\end{tabular}

Multivariable logistic regression adjusted for age, sex, smoking, and body mass index. ${ }^{*} P<0.05$.

$\mathrm{Cl}$, confidence interval.

(MRI). Exercise leads to diverse benefits that may prevent chronic disease, including rheumatoid arthritis and diabetes.

The current study demonstrated that older adults with higher handgrip strength had lower rates of rheumatoid arthritis and diabetes. The results of this study coincide with those of previous studies, in which patients with type 2 diabetes mellitus had lower handgrip strength compared with healthy participants. ${ }^{16}$ Several studies have reported that diabetes patients exhibit muscle weakness, as measured by manual muscle testing, isokinetic dynamometry, MRI, and handgrip strength. ${ }^{17-20}$ The diabetic patients had distal muscle weakness that led to symmetrical sensory neuropathy. It has been shown that hand function is an important indicator of rheumatoid arthritis status, ${ }^{21}$ and that rheumatoid arthritis patients have a reduction in grip force compared with healthy individuals. ${ }^{22}$ Handgrip strength in rheumatoid arthritis patients has also been shown to be associated with quality of life. ${ }^{23}$ Previous studies have reported that diabetes is associated with rheumatoid arthritis. ${ }^{24,25}$ Patients with chronic inflammation in rheumatoid arthritis and diabetes show increased levels of CRP and IL-6. However, Simard and
Mittleman ${ }^{26}$ conducted a cross-sectional study of a limited number of patients with rheumatoid arthritis and reported no association between rheumatoid arthritis and diabetes in American older adults. The current study also failed to find an association between rheumatoid arthritis and diabetes in older Koreans. This was also a cross-sectional study with a relatively small number of older Korean patients with rheumatoid arthritis and diabetes. Thus, a longitudinal study is warranted.

There are several possible mechanisms through which rheumatoid arthritis and diabetes may be related and through which higher handgrip strength reduces the prevalence of rheumatoid arthritis and diabetes. First, microvascular disease and ischemia produce free radical oxygen species that damage cells. ${ }^{27}$ Second, advanced glycation end products accumulate in connective tissue, changing the structure and function of the extracellular matrix and affecting the viability of cells. ${ }^{28}$ Third, activation of platelets and macrophages by ischemia promotes secretion of several cytokines that result from production of collagen and the process of fibrosis. ${ }^{7,29,30}$ Rheumatoid disease comorbidities are commonly encountered in patients with diabetes and include diabetic and neuropathic arthropathy, trigger finger, wrist osteoarthritis, adhesion capsulitis, generalized idiopathic skeletal hyperostosis, gouty arthritis, osteoarthritis, or rheumatoid arthritis. ${ }^{30}$ However, exercise decreases the detrimental effects of free radical oxygen species and the inflammatory effects of CRP. ${ }^{31}$

This study had limitations. First, as a cross-sectional study, it was not designed to identify causality. It cannot be determined whether handgrip strength is an independent causative factor of rheumatoid arthritis and diabetes or an epiphenomenon of rheumatoid arthritis and diabetes among older adults. Further studies that include longitudinal data are required to confirm causality. Second, physical activity and presence of rheumatoid arthritis and diabetes were selfreported data, while handgrip strength was objectively measured. Self-reported data may result in recall and social desirability biases.

In conclusion, older adults who take part in walking and perform strength and flexibility exercises had higher handgrip strength than older adults who did not participate in such physical activities. As handgrip strength increased, older adults had lower rates of rheumatoid arthritis and diabetes. To improve handgrip strength in older adults, participation in physical activities such as walking and 
strength and flexibility exercises is required.

\section{CONFLICTS OF INTEREST}

The authors declare no conflict of interest.

\section{ACKNOWLEDGMENTS}

The authors would like to thank all subjects for participating in the National Health and Nutrition Examination Survey.

\section{AUTHOR CONTRIBUTIONS}

Study concept and design: all authors; acquisition of data: all authors; analysis and interpretation of data: all authors; drafting of the manuscript: JL; critical revision of the manuscript: MGL; statistical analysis: all authors; administrative, technical, or material support: all authors; and study supervision: all authors.

\section{REFERENCES}

1. World Health Organization. WHO methods for life expectancy and healthy life expectancy. Geneva: World Health Organization; 2015.

2. Rijk JM, Roos PR, Deckx L, van den Akker M, Buntinx F. Prognostic value of handgrip strength in people aged 60 years and older: a systematic review and meta-analysis. Geriatr Gerontol Int 2016;16:5-20.

3. Buchman AS, Wilson RS, Boyle PA, Bienias JL, Bennett DA. Grip strength and the risk of incident Alzheimer's disease. Neuroepidemiology 2007;29:66-73.

4. Chu LW, Chi I, Chiu AY. Incidence and predictors of falls in the Chinese elderly. Ann Acad Med Singapore 2005;34:60-72.

5. Cheung CL, Nguyen US, Au E, Tan KC, Kung AW. Association of handgrip strength with chronic diseases and multimorbidity: a cross-sectional study. Age (Dordr) 2013;35:929-41.

6. Korea Centers for Disease Control and Prevention. Korean chronic diseases statistics. Cheongju: Korea Centers for Disease Control and Prevention; 2016.

7. Al-Homood IA. Rheumatic conditions in patients with diabetes mellitus. Clin Rheumatol 2013;32:527-33.

8. Doran M. Rheumatoid arthritis and diabetes mellitus: evidence for an association? J Rheumatol 2007;34:460-2.

9. Leenders M, Verdijk LB, van der Hoeven L, Adam JJ, van Kranenburg J, Nilwik R, et al. Patients with type 2 diabetes show a greater decline in muscle mass, muscle strength, and functional capacity with aging. J Am Med Dir Assoc 2013;14: 585-92.

10. Cooney JK, Law RJ, Matschke V, Lemmey AB, Moore JP, Ahmad Y, et al. Benefits of exercise in rheumatoid arthritis. J Aging Res 2011;2011:681640.

11. No JK. Evaluation of dietary intake and exercise in the elderly according to hand grip strength. Korean J Obes 2013;22:24350.

12. Minor MA, Hewett JE, Webel RR, Anderson SK, Kay DR. Efficacy of physical conditioning exercise in patients with rheumatoid arthritis and osteoarthritis. Arthritis Rheum 1989;32: 1396-405.

13. Rall LC, Rosen CJ, Dolnikowski G, Hartman WJ, Lundgren N, Abad LW, et al. Protein metabolism in rheumatoid arthritis and aging: effects of muscle strength training and tumor necrosis factor alpha. Arthritis Rheum 1996;39:1115-24.

14. Manning VL, Hurley MV, Scott DL, Coker B, Choy E, Bearne LM. Education, self-management, and upper extremity exercise training in people with rheumatoid arthritis: a randomized controlled trial. Arthritis Care Res (Hoboken) 2014;66:217-27.

15. Speed CA, Campbell R. Mechanisms of strength gain in a handgrip exercise programme in rheumatoid arthritis. Rheumatol Int 2012;32:159-63.

16. Cichosz SL, Vestergaard ET, Hejlesen O. Muscle grip strength is associated to reduced pulmonary capacity in patients with diabetes. Prim Care Diabetes 2018;12:66-70.

17. Cetinus E, Buyukbese MA, Uzel M, Ekerbicer H, Karaoguz A. Hand grip strength in patients with type 2 diabetes mellitus. Diabetes Res Clin Pract 2005;70:278-86.

18. Bus SA, Yang QX, Wang JH, Smith MB, Wunderlich R, Cavanagh PR. Intrinsic muscle atrophy and toe deformity in the diabetic neuropathic foot: a magnetic resonance imaging study. Diabetes Care 2002;25:1444-50.

19. Dyck PJ, Kratz KM, Karnes JL, Litchy WJ, Klein R, Pach JM, 
et al. The prevalence by staged severity of various types of diabetic neuropathy, retinopathy, and nephropathy in a populationbased cohort: the Rochester Diabetic Neuropathy Study. Neurology 1993;43:817-24.

20. Andersen H, Poulsen PL, Mogensen CE, Jakobsen J. Isokinetic muscle strength in long-term IDDM patients in relation to diabetic complications. Diabetes 1996;45:440-5.

21. Espinoza F, Le Blay P, Coulon D, Lieu S, Munro J, Jorgensen C, et al. Handgrip strength measured by a dynamometer connected to a smartphone: a new applied health technology solution for the self-assessment of rheumatoid arthritis disease activity. Rheumatology (Oxford) 2016;55:897-901.

22. Nordenskiöld UM, Grimby G. Grip force in patients with rheumatoid arthritis and fibromyalgia and in healthy subjects: a study with the Grippit instrument. Scand J Rheumatol 1993; 22:14-9.

23. Waljee JF, Chung KC, Kim HM, Burns PB, Burke FD, Wilgis EF, et al. Validity and responsiveness of the Michigan Hand Questionnaire in patients with rheumatoid arthritis: a multicenter, international study. Arthritis Care Res (Hoboken) 2010; 62:1569-77.

24. Dessein PH, Joffe BI, Stanwix A, Botha AS, Moomal Z. The acute phase response does not fully predict the presence of insulin resistance and dyslipidemia in inflammatory arthritis. J
Rheumatol 2002;29:462-6.

25. Solomon DH, Karlson EW, Rimm EB, Cannuscio CC, Mandl LA, Manson JE, et al. Cardiovascular morbidity and mortality in women diagnosed with rheumatoid arthritis. Circulation 2003;107:1303-7.

26. Simard JF, Mittleman MA. Prevalent rheumatoid arthritis and diabetes among NHANES III participants aged 60 and older. J Rheumatol 2007;34:469-73.

27. Hensley K, Robinson KA, Gabbita SP, Salsman S, Floyd RA. Reactive oxygen species, cell signaling, and cell injury. Free Radic Biol Med 2000;28:1456-62.

28. Schleicher ED, Wagner E, Nerlich AG. Increased accumulation of the glycoxidation product $\mathrm{N}$ (epsilon)-(carboxymethyl)lysine in human tissues in diabetes and aging. J Clin Invest 1997;99: 457-68.

29. Jacobs-Kosmin D, DeHoratius RJ. Musculoskeletal manifestations of endocrine disorders. Curr Opin Rheumatol 2005;17: 64-9.

30. Burner TW, Rosenthal AK. Diabetes and rheumatic diseases. Curr Opin Rheumatol 2009;21:50-4.

31. Ford ES. Does exercise reduce inflammation? Physical activity and C-reactive protein among U.S. adults. Epidemiology 2002; 13:561-8. 